\title{
Coupled Changes in Brain White Matter Microstructure and Fluid Intelligence in Later Life
}

\author{
Stuart J. Ritchie, ${ }^{1,2 *}$ Mark E. Bastin, ${ }^{2,4,5,6 *}$ Elliot M. Tucker-Drob, ${ }^{7 \star}$ Susana Muñoz Maniega, ${ }^{2,4,5,6}$ \\ ○Laura E. Engelhardt, ${ }^{7}$ Simon R. Cox, ${ }^{1,2}$ Natalie A. Royle,,${ }^{2,4,5,6}$ Alan J. Gow, ${ }^{2,8}$ Janie Corley, ${ }^{1}$ Alison Pattie, ${ }^{1}$ \\ (D)Adele M. Taylor, ${ }^{1}$ Maria del C. Valdés Hernández, ${ }^{2,4,5,6}$ John M Starr, ${ }^{2,3}$ (D) Joanna M. Wardlaw, ${ }^{2,4,5,6}$ and Ian J. Deary ${ }^{1,2}$ \\ ${ }^{1}$ Department of Psychology, ${ }^{2}$ Centre for Cognitive Ageing and Cognitive Epidemiology, and ${ }^{3}$ Alzheimer Scotland Dementia Research Centre, The University \\ of Edinburgh, Edinburgh EH8 9JZ, UK, ${ }^{4}$ Centre for Clinical Brain Sciences, The University of Edinburgh, Edinburgh EH16 4SA, UK, ${ }^{5}$ Brain Research \\ Imaging Centre, The University of Edinburgh, Edinburgh EH4 2XU, UK, ${ }^{6}$ Scottish Imaging Network, a Platform for Scientific Excellence (SINAPSE), \\ Edinburgh, UK, ${ }^{7}$ Department of Psychology, University of Texas, Austin, Texas 78712-0187, and ${ }^{8}$ Department of Psychology, Heriot-Watt University, \\ Edinburgh EH14 4AS, UK
}

Understanding aging-related cognitive decline is of growing importance in aging societies, but relatively little is known about its neural substrates. Measures of white matter microstructure are known to correlate cross-sectionally with cognitive ability measures, but only a few small studies have tested for longitudinal relations among these variables. We tested whether there were coupled changes in brain white matter microstructure indexed by fractional anisotropy (FA) and three broad cognitive domains (fluid intelligence, processing speed, and memory) in a large cohort of human participants with longitudinal diffusion tensor MRI and detailed cognitive data taken at ages 73 years $(n=731)$ and 76 years $(n=488)$. Longitudinal changes in white matter microstructure were coupled with changes in fluid intelligence, but not with processing speed or memory. Individuals with higher baseline white matter FA showed less subsequent decline in processing speed. Our results provide evidence for a longitudinal link between changes in white matter microstructure and agingrelated cognitive decline during the eighth decade of life. They are consistent with theoretical perspectives positing that a corticocortical "disconnection" partly explains cognitive aging.

Key words: cognitive aging; diffusion tensor imaging; fluid intelligence; fractional anisotropy; processing speed; white matter microstructure

\section{Introduction}

Aging-related cognitive decline is a growing psychiatric, economic, and social burden for countries with aging populations.

\footnotetext{
Received March 5, 2015; revised April 12, 2015; accepted April 25, 2015.

Author contributions:S.J.R., M.E.B., E.M.T.-D., J.M.S., J.M.W., and I.J.D. designed research;S.J.R., M.E.B., S.M.M., S.R.C., N.A.R., A.J.G., J.C., A.P., A.M.T., M.d.C.V.H., and J.M.W. performed research; M.E.B., S.M.M., S.R.C., N.A.R., M.d.C.V.H., and J.M.W. contributed unpublished reagents/analytic tools; S.J.R., E.M.T.-D., and L.E.E. analyzed data; S.J.R., M.E.B., E.M.T.-D., and I.J.D. wrote the paper.

Data collection from the Lothian Birth Cohort 1936 (LBC1936) was supported by the Disconnected Mind project, funded by Age UK. S.J.R. is funded by the UK Medical Research Council (MRC). J.M.W. is partly funded by the Scottish Funding Council as part of the SINAPSE Collaboration. The work was undertaken by The University of Edinburgh Centre for Cognitive Ageing and Cognitive Epidemiology, part of the cross-council Lifelong Health and Wellbeing Initiative (MR/K026992/1). Funding from the Biotechnology and Biological Sciences Research Council (BBSRC) and MRC is gratefully acknowledged. We thank the LBC1936 members for their participation. We also thank Catherine Murray, Caroline Brett, and Ross Henderson for data collection and data entry; the nurses, radiographers, and other staff at the Wellcome Trust Clinical Research Facility and the Brain Research Imaging Centre; and the staff at Lothian Health Board and at the Scottish Council for Research in Education Centre, University of Glasgow.

*S.J.R., M.E.B., and E.M.T.-D. contributed equally to this work.

The authors declare no competing financial interests.

This article is freely available online through the J Neurosci Author Open Choice option.

Correspondence should be addressed to Stuart J. Ritchie, Centre for Cognitive Ageing and Cognitive Epidemiology, The University of Edinburgh, 7 George Square, Edinburgh EH8 9JZ, UK. E-mail: stuart.ritchie@ed.ac.uk.

DOI:10.1523/JNEUROSCI.0862-15.2015

Copyright $\odot 2015$ Ritchie et al.

This is an Open Access article distributed under the terms of the Creative Commons Attribution License Creative Commons Attribution 4.0 International, which permits unrestricted use, distribution and reproduction in any medium provided that the original work is properly attributed.
}

Gaining a more complete understanding of normal cognitive aging is of great importance for future efforts to predict and treat dementia and other related pathologies (Boyle et al., 2013). Despite the increasing importance of cognitive decline, a recent review (Salthouse, 2011) concluded that little is known about its neurobiological substrates. It is rare for studies to examine longitudinal trends in both cognitive ability and in neuroimaging measurements, and even rarer for them to include large samples with a narrow age range (Charlton et al., 2010; Lövdén et al., 2014). Here, we report a study that analyzed longitudinal cognitive and brain imaging data in a large sample, using structural equation modeling to test the hypothesis that the disconnection of brain regions is among the causes of cognitive decline in older age (Geschwind, 1965; Bennett and Madden, 2014). We tested whether changes in the white matter microstructure of the brain during the eighth decade of life are associated with changes in the key cognitive domains of general fluid intelligence $\left(g_{f}\right)$, cognitive processing speed, and memory.

We measured the white matter microstructure of the brain using diffusion tensor magnetic resonance imaging (DT-MRI; Chanraud et al., 2010) and probabilistic neighborhood tractography (Clayden et al., 2011), which provided tract-averaged measures of fractional anisotropy (FA) for a range of major association, projection, and commissural fibers. FA measures the di- 
rectional coherence of water molecule diffusion in the white matter of the brain. Higher directional coherence (higher FA) indicates a greater constraint on water molecule diffusion along the principal fiber direction by axonal membranes and surrounding myelin, and, potentially, more efficient transfer of information. It thus provides a biomarker for white matter microstructure (Le Behan, 2003).

Higher FA in specific white matter tracts, and across broader regions of white matter, has been linked cross-sectionally to better scores on various cognitive tests (Grieve et al., 2007; Turken et al., 2008; Penke et al., 2010, 2012). Researchers have therefore concluded that white matter microstructure plays a part in the neural basis of cognitive ability. Like cognitive ability, FA begins to decline with age at or around the beginning of the third decade of life, with steeper declines observed later in the life course (Salat et al., 2005; Sullivan et al., 2010; Kochunov et al., 2012; Lebel et al., 2012). This raises the important question of whether declines in white matter microstructure share any of their variance with declines in cognitive ability. Cross-sectional studies have begun to answer this question, showing that measures of white matter microstructure mediate associations of age with cognitive abilities (Madden et al., 2009; Voineskos et al., 2012; Borghesani et al., 2013; Kievit et al., 2014). However, longitudinal studies are crucial for directly testing whether changes in brain structure are associated with changes in cognitive ability (Raz and Lindenberger, 2011).

Only two previous studies, to our knowledge, have addressed coupled longitudinal change in white matter microstructure and cognitive abilities during aging. The first (Charlton et al., 2010) found a significant correlation of $r=0.329$ between decline over 2 years in white matter mean diffusivity (MD; an alternative measure of white matter microstructure) and contemporaneous decline in working memory. The second (Lövdén et al., 2014) showed strong correlations between the decline in white matter FA and MD in the corticospinal tract across 2.3 years and a measure of perceptual speed. However, both studies had relatively small longitudinally imaged samples $(n=84$ and 40 , respectively), and their wide age ranges (55-90 years and 81-103 years, respectively) risk confounding in between-person and withinperson age differences (Hofer and Sliwinski, 2001). Largesample, narrow age range cohort designs, as in the present study, minimize these potential sources of error.

In the present study, we modeled relations between white matter FA and cognitive abilities in a large, narrow age range birth cohort sample, with a follow-up period of 3 years (from a mean age of 73 to 76 years). We used latent variable modeling to reduce measurement error, and assessed the relationship of change in broad general factors of fluid intelligence, processing speed, and memory with change in general white matter tract FA.

\section{Materials and Methods}

\section{Participants}

The Lothian Birth Cohort 1936 is a longitudinally studied sample of individuals, most of whom took part in the Scottish Mental Survey 1947, when they were $\sim 11$ years of age (Scottish Council for Research in Education, 1949). The sample has repeatedly been tested in later life. The first testing wave took place at a mean age of 69.53 years (SD, 0.83 years) in 2004-2007 ( $n=1091,543$ females); the second testing wave took place at a mean age of 72.49 years (SD, 0.71 years $)$ in $2007-2010(n=866,418$ females); and the third testing wave took place at a mean age of 76.25 years (SD, 0.68 years) in 2011-2014 ( $n=697,337$ females). Full details on the cohort are available elsewhere (Deary et al., 2007, 2012). All participants provided written informed consent before testing. The Lothian Birth Cohort 1936 study was approved by the Multi-Centre Research
Ethics Committee for Scotland (MREC/01/0/56) and the Lothian Research Ethics Committee (LREC/2003/2/29).

The data in the present study come from the second and third waves, at which points structural brain imaging was also undertaken (see below for neuroimaging procedures). Imaging took place at a different session to the cognitive testing, with an average of $65.04 \mathrm{~d}$ between sessions at the second wave (SD, $39.57 \mathrm{~d}$ ) and $40.29 \mathrm{~d}$ at the third wave (SD, $31.89 \mathrm{~d}$ ). A total of 731 participants (343 females) underwent brain imaging at a mean age of 72.68 years (SD, 0.72 years), and 488 ( 228 females) at a mean age of 76.38 years (SD, 0.65 years). Not all participants provided usable data; valid sample sizes for each individual brain measure are shown in Table 1.

\section{Measures}

Cognitive ability. A wide range of cognitive ability measures was completed by the cohort members at each of the waves. The tests described here, grouped by the cognitive domain to which they contributed, were administered identically at the second and third waves of the study. All have been described in detail previously (Deary et al., 2007). $g_{f}$ consisted of the following four tests, all from the Wechsler Adult Intelligence Scale, third UK Edition (WAIS-III-UK; Wechsler, 1998): Matrix Reasoning and Block Design (which mainly assess nonverbal and spatial reasoning); and Digit Span Backward and Letter-Number Sequencing (mainly tests of working memory). Processing speed consisted of the following five tests: WAIS Digit-Symbol Substitution and Symbol Search (both speeded pencil-and-paper tasks), Simple Reaction Time, and 4-Choice Reaction Time (tested using a dedicated measurement instrument; Deary et al., 2001; Simple Reaction Time was log transformed before inclusion in the analyses), and Inspection Time (a computerized test of visual discrimination speed; Deary et al., 2004). Finally, memory consisted of the following three tests from the WMS-III-UK (Wechsler, 1998): Logical Memory (indexing verbal declarative memory; total score from immediate and delayed); Spatial Span (total from forward and backward tests); and Verbal Paired Associates (total from immediate and delayed tests). Valid sample sizes for each individual cognitive variable are shown in Table 2.

Diffusion tensor MRI. The neuroimaging protocol for the study was fully described previously (Wardlaw et al., 2011). The second and third waves of the study had an identical imaging protocol, using the exact same scanner, maintained to operate as consistently as possible across time. Subjects were scanned using a Signa HDxt 1.5 T scanner (GE Healthcare) with a self-shielding gradient set (maximum gradient strength, $33 \mathrm{mT} / \mathrm{m}$ ) and an eight-channel phased-array head coil. The whole-brain DT-MRI examination consisted of seven $\mathrm{T}_{2}$-weighted $(b=$ $\left.0 \mathrm{~s} / \mathrm{mm}^{2}\right)$ and sets of diffusion-weighted $\left(b=1000 \mathrm{~s} / \mathrm{mm}^{2}\right)$ single-shot spin echo echoplanar imaging (EPI) volumes acquired with diffusion gradients applied in 64 noncollinear directions (Jones et al., 2002). These data were acquired in the axial plane, with a field of view of $256 \times 256$ $\mathrm{mm}, 72$ contiguous slice locations, and an imaging matrix $(128 \times 128)$ and slice thickness $(2 \mathrm{~mm})$ designed to give $2 \mathrm{~mm}$ isotropic voxels. The repetition and echo times for the EPI sequence were $16.5 \mathrm{~s}$ and $98.3 \mathrm{~ms}$, respectively.

Tractography. All MRI data were converted from DICOM (http://dicom.nema.org/) to NIfTI-1 (http://nifti.nimh.nih.gov/nifti-1/) format, and preprocessed with FSL tools (http://www.fmrib.ox.ac.uk/fsl/) to extract the brain, eliminate bulk patient motion and eddy current-induced artifacts, and estimate FA in each brain voxel (Pierpaoli et al., 1996). The underlying connectivity data were generated using BedpostX/ProbTrackX (Behrens et al., 2007), with a two-fiber model and 5000 streamlines to reconstruct tracts of interest.

Probabilistic neighborhood tractography (Clayden et al., 2011), an automatic tract segmentation method with good reproducibility, was implemented in the TractoR package for R (http://www.tractor-mri.org. $\mathrm{uk}$ ); this method provides intrasubject coefficients of variation across multiple measurements of typically $<10 \%$ for tract-averaged FA (Clayden et al., 2009). We identified 12 tracts of interest in each participant based on tract topology models: the genu and splenium of the corpus callosum, the bilateral rostral cingulum cingulate gyri, the bilateral arcuate, uncinate, and inferior longitudinal fasciculi, and the bilat- 


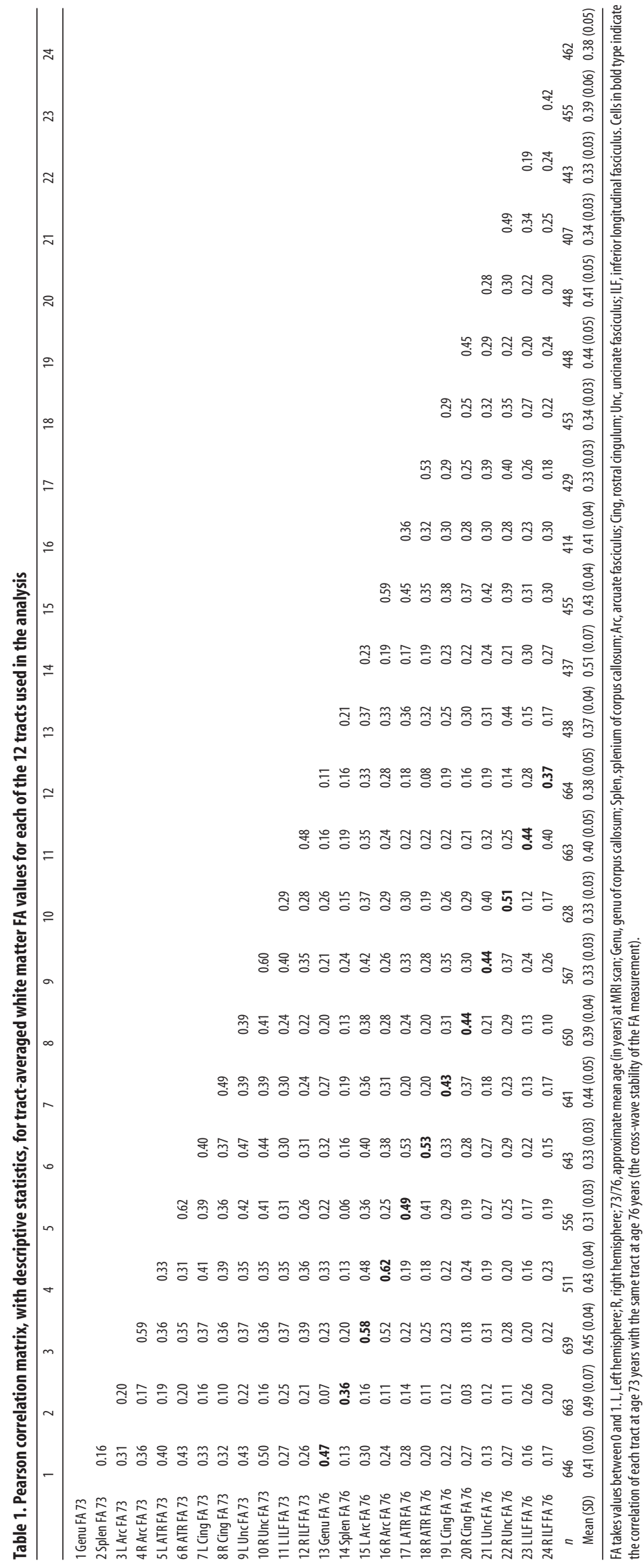




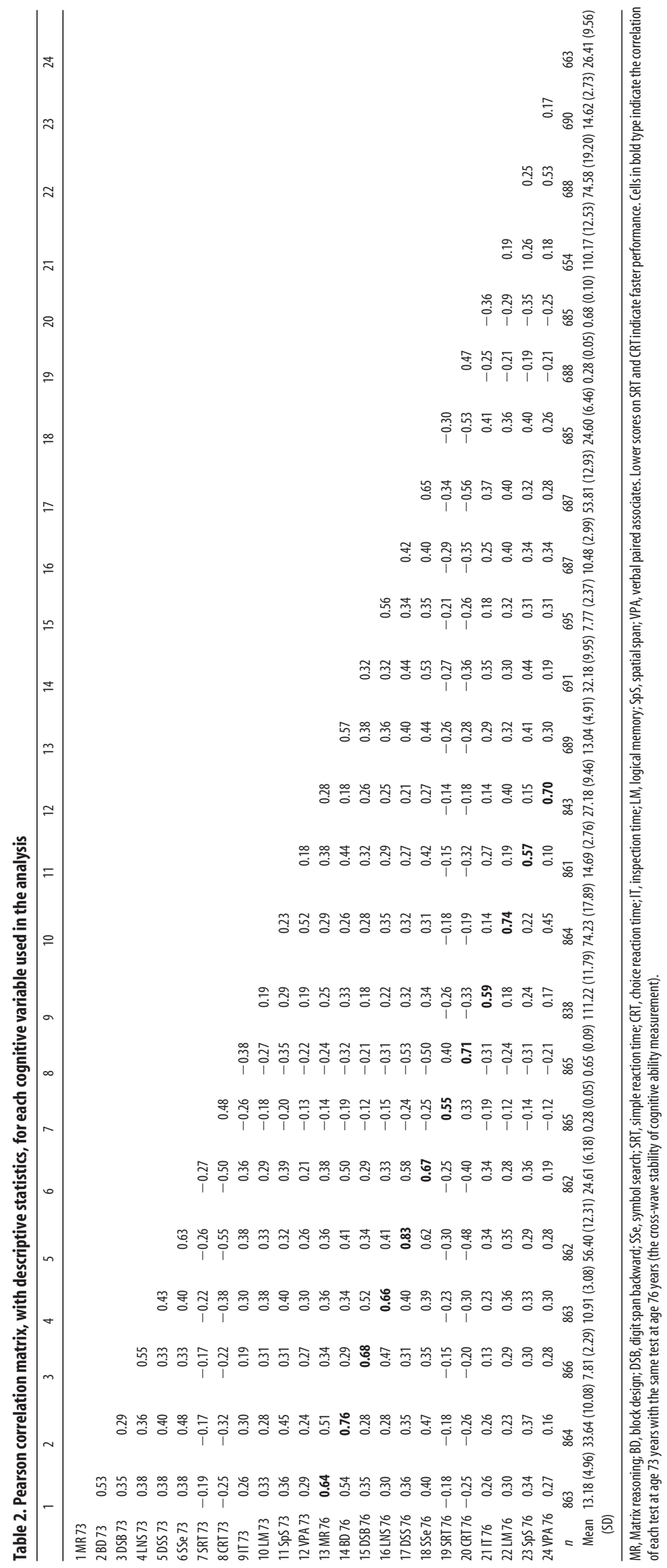




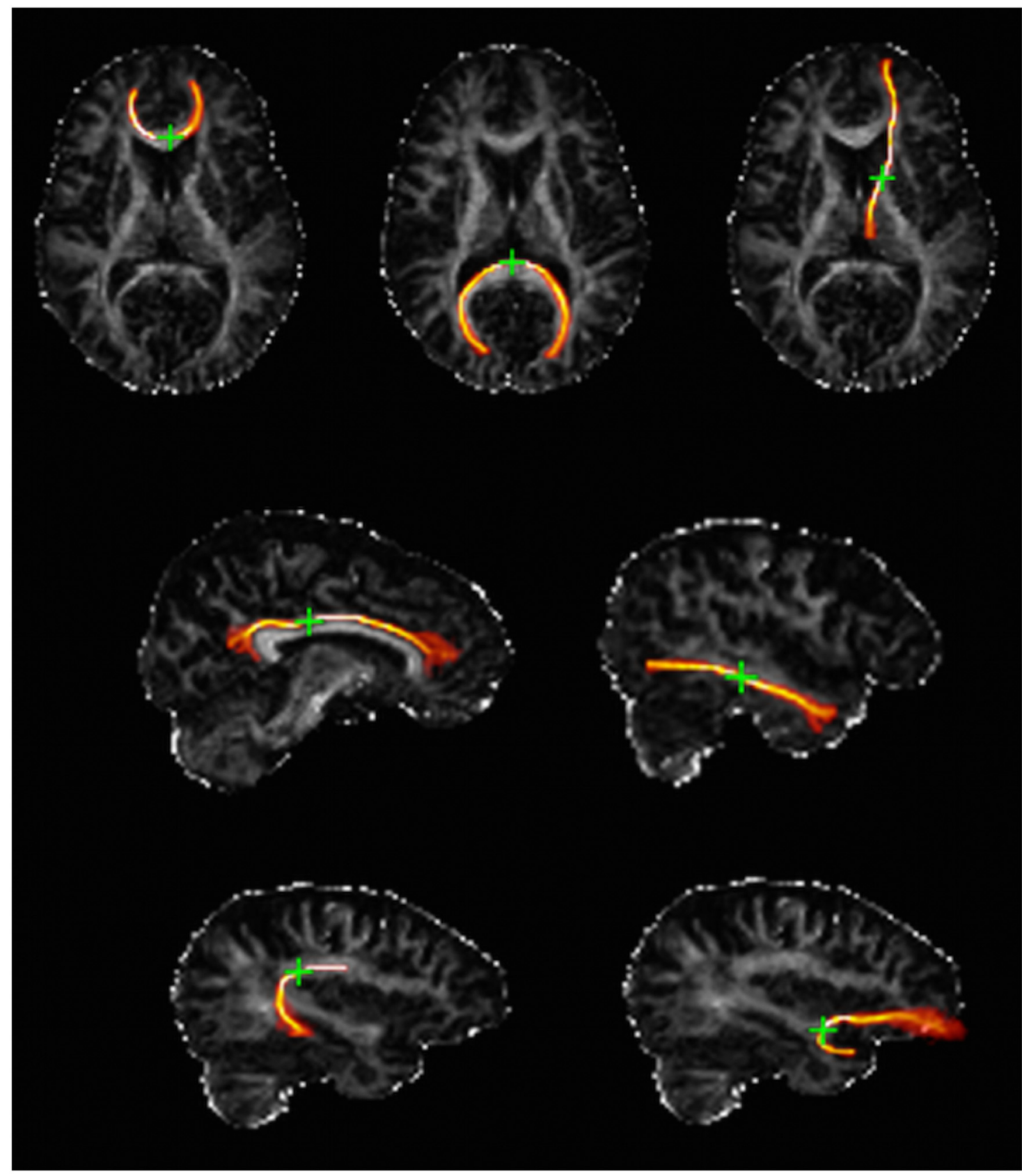

Figure 1. Examples of major white matter tracts segmented using probabilistic neighborhood tractography overlaid on fractional anisotropy maps for a representative subject; segmented white matter tracts are shown in orange, with seed points indicated with a green cross. Top row (left to right), Genu of corpus callosum, splenium of corpus callosum, and anterior thalamic radiation. Middle row (left to right), rostral cingulum and inferior longitudinal fasciculus. Bottom row (left to right), Arcuate fasciculus and uncinate fasciculus. The latter five tracts were measured for both the left and right hemispheres, giving a total of 12 tracts. Tracts were measured and processed in an identical fashion at both the age $\sim 73$ years and age $\sim 76$ years measurement waves.

eral anterior thalamic radiations (Fig. 1). This method selects the optimal choice of tractography seed point by estimating the best-matching tract, in terms of length and shape relative to a previously defined reference tract, from a large number of candidates generated from a neighborhood of seed points (typically $7 \times 7 \times 7$ voxels) placed around a central seed transferred from standard space. These topological tract models also allow for rejection of false-positive connections (Clayden et al., 2011), thereby significantly improving the tract segmentation (Bastin et al., 2010). The seed point best matching each tract to the reference was determined in this manner, with the resulting tractography mask applied to the FA volumes of each participant. This permitted tract-specific mean values of this biomarker, weighted by the connection probability, to be determined for each tract in each subject. Finally, segmented tracts were excluded if there was evidence of aberrant or truncated pathways that did not appear to be anatomically plausible representations of tracts. Note that the image analysts using TractoR were blind to the characteristics (including, at the second wave, the previous DT-MRI biomarker values) of each participant.

\section{Statistical analysis}

The analyses were based on the universal finding of positive manifolds of correlations between scores on cognitive tests (Carroll, 1993), and our finding of positive correlations among tract-averaged FA values for individual white matter tracts (Penke et al., 2010). That is, variables from within each set of measures of cognitive ability (fluid intelligence, processing speed, and memory) were positively intercorrelated, as were tract-averaged FA values for all 12 major tracts. This allowed four common, latent factors reflecting fluid intelligence, memory, processing speed, and 


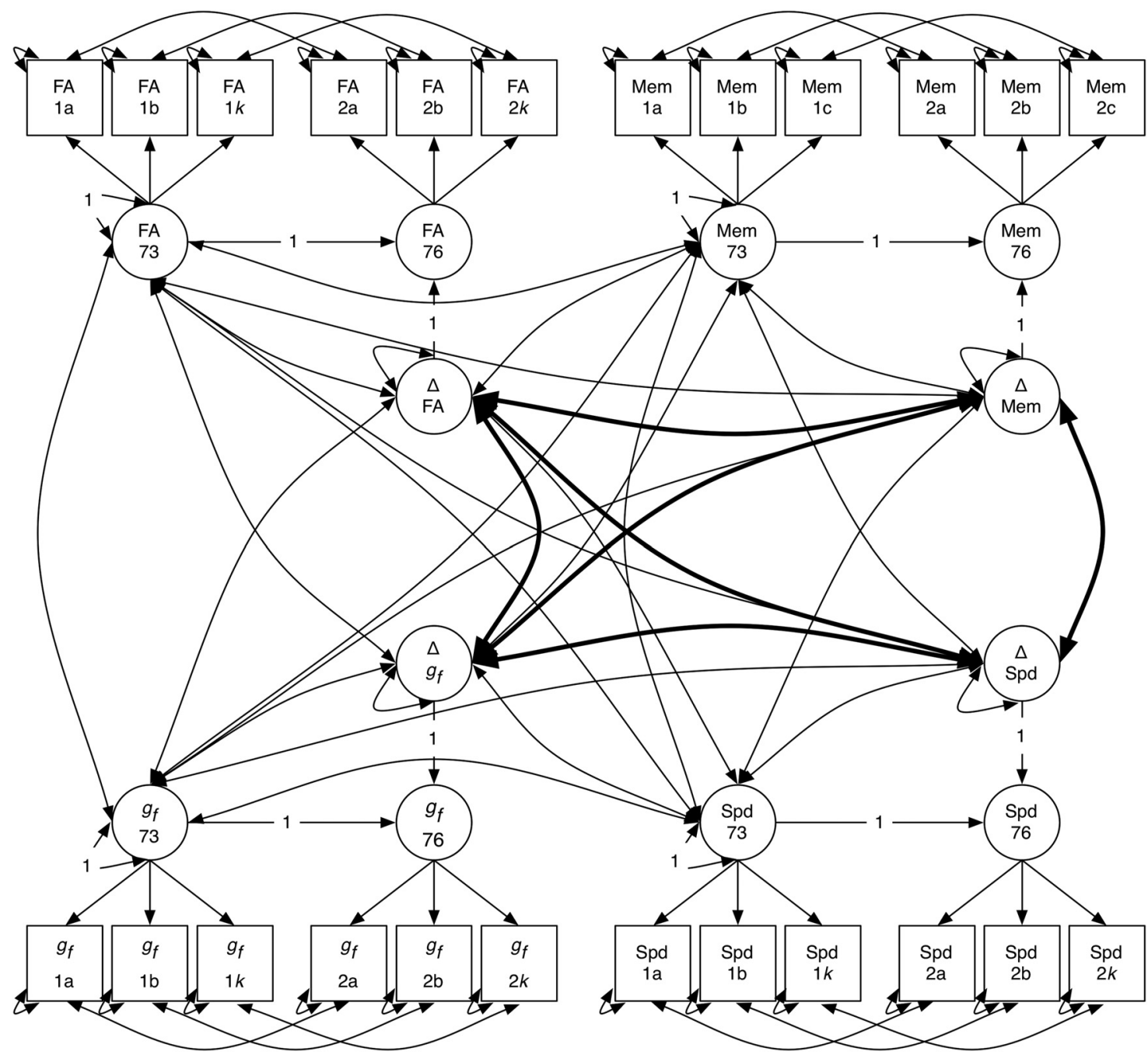

Figure 2. Full path diagram for the four-way multivariate latent difference score model. For each variable, two latent factors (circles; age 73 and 76 years) are estimated from the manifest indicators (squares, 1a- $k$ and 2a- $k$ ), and a latent change factor is calculated from the change between age 73 and 76 years (circles, $\Delta$ ). Bolded paths indicate change-change correlations, the main paths of interest in the present study. For space reasons, only three manifest variables are shown for each latent factor; in the model: $F A, g_{f t}$ and processing speed were all estimated using more than three indicators (12, 4, and 4, respectively). Paths labeled " 1 " were fixed to 1 to identify the model and estimate the latent change factor. For clarity, the model mean structure is not shown. Mem, Memory; Spd, processing speed.

white matter FA to be modeled, and their fit to the data tested, at each of the two measurement waves. Each individual test or tract has a loading that indexes how strongly it relates to the relevant latent general factor.

The latent general factors were used in a multivariate Latent Difference Score structural equation model (McArdle, 2009), shown in full in Figure 2). Mplus version 7.11 was used for all modeling (Muthén and Muthén, 1998-2014). As is standard in longitudinal data analysis with latent variables, we used full information maximum likelihood estimation to deal with missing data under the "missing at random" assumption. This assumes that any systematic associations between patterns of missingness and the missing scores themselves can be statistically accounted for by the data present in the model. In the model, latent difference scores were calculated from changes in the latent factor scores between the measurement waves. These latent difference scores are free of measurement errors associated with specific tests and tracts, since they index only the shared variance between the multiple indicators.

Correlations among the cognitive and FA factors, between the factors and the difference scores, and among the difference scores were simultaneously estimated within the model. We also allowed cross-loadings between cognitive factors: Digit-Symbol Substitution and Symbol Search loaded on both the $g_{f}$ and speed factors. This cross-loading improved model fit but did not appreciably alter the results reported below. Since there was some age variance at the two measurement waves, and there may also have been confounding effects of sex, each measurement was residualized for age (in days) and sex before including it in the model. We tested whether there were significant differences between the effect sizes of key correlations by constraining them to equality in a new model, then comparing it to the original model using a $\chi^{2}$ test. If the fit of the new model was significantly poorer, this indicated that the correlations were significantly different in size.

We assumed that each factor measured the same trait across time (i.e., we assumed strong factorial invariance; Widaman et al., 2010) and implemented this in the model by setting the loadings of each of the factor indicators and their intercepts equal across waves. For all three cognitive factors, tests supported invariance of both loadings and intercepts. For the white matter FA factor, tests supported invariance of the loadings, but a model with freely estimated intercepts was superior to one with invariance. Relaxing the invariance assumption for the FA intercepts produced results that were very similar to those in the main analysis for change in FA and change in $g_{f}$, and for baseline FA and change in speed.

\section{Results}

The cognitive factors and the general FA values showed high reliability: the cross-wave correlation for general FA was $r=0.65$; for $g_{f}$, speed, and memory, the correlations were $r=0.85,0.86$, 
Table 3. Factor loadings from the measurement model of the multivariate latent change model of white matter $\mathrm{FA}, \boldsymbol{g}_{\boldsymbol{f}}$ memory, and processing speed (reaction times are recalculated so that higher values indicate better scores)

\begin{tabular}{lllll}
\hline Factor & Variable & Estimate & SE & $p$ value \\
\hline FA & Genu of the corpus callosum & 0.597 & 0.027 & $<0.001$ \\
& Splenium of the corpus callosum & 0.344 & 0.033 & $<0.001$ \\
& Left arcuate fasciculus & 0.653 & 0.024 & $<0.001$ \\
& Right arcuate fasciculus & 0.613 & 0.028 & $<0.001$ \\
& Left anterior thalamic radiation & 0.645 & 0.026 & $<0.001$ \\
& Right anterior thalamic radiation & 0.661 & 0.025 & $<0.001$ \\
& Left rostral cingulum & 0.600 & 0.027 & $<0.001$ \\
& Right rostral cingulum & 0.552 & 0.028 & $<0.001$ \\
& Left uncinate fasciculus & 0.679 & 0.025 & $<0.001$ \\
& Right uncinate fasciculus & 0.669 & 0.025 & $<0.001$ \\
& Left inferior longitudinal fasciculus & 0.523 & 0.030 & $<0.001$ \\
& Right inferior longitudinal fasciculus & 0.488 & 0.030 & $<0.001$ \\
& Matrix reasoning & 0.648 & 0.022 & $<0.001$ \\
$g_{f}$ & 0.669 & 0.022 & $<0.001$ \\
& Block design & 0.586 & 0.025 & $<0.001$ \\
& Digit span backward & 0.658 & 0.023 & $<0.001$ \\
& Letter-number sequencing & 0.306 & 0.052 & $<0.001$ \\
& Digit-symbol substitution & 0.378 & 0.047 & $<0.001$ \\
& Symbol search & 0.527 & 0.049 & $<0.001$ \\
Speed & Digit-symbol substitution & 0.429 & 0.045 & $<0.001$ \\
& Symbol search & 0.496 & 0.028 & $<0.001$ \\
& Simple reaction time & 0.795 & 0.023 & $<0.001$ \\
& Choice reaction time & 0.522 & 0.026 & $<0.001$ \\
& Inspection time & 0.614 & 0.033 & $<0.001$ \\
& Logical memory & 0.546 & 0.029 & $<0.001$ \\
Memory & Spatial span & 0.560 & 0.034 & $<0.001$ \\
& Verbal paired associates & &
\end{tabular}

Due to the invariance assumption, factor loadings and indicator intercepts were identical at waves 1 and 2. Digitsymbol substitution and Symbol search loaded on both $g_{f}$ and speed. The full model diagram is shown in Figure 2 . Results taken from the model are adjusted for age at testing and sex. All estimates are standardized.

and 0.76 , respectively. For the 12 individual tracts, the cross-wave FA correlations ranged from $r=0.36$ to $r=0.62$ (mean $r=0.47$; Table 1). For the individual cognitive tests in the $g_{f}$, speed, and memory domains, the mean cross-wave correlations were $r=$ $0.69,0.69$, and 0.67 , respectively (Table 2 ). Loadings for each of the factors (from the measurement model) are provided in Table 3. Factor loadings were all statistically significant and substantial: most had moderate-to-large effect sizes (around or above $r=$ 0.60 ), indicating that these factors were good indices of the common variance within each cognitive domain and within white matter tract FA values. For $g_{f}$, the two speed tests that were crossloaded on this factor and on the speed factor had lower $g_{f}$ loadings than the four nonspeeded tests. For speed, the highest loading was that of Choice Reaction Time, with each of the other tests loading similarly strongly. For memory, the three tests had similar loadings. FA in the splenium of the corpus callosum had the lowest loading on the general factor of FA, while all the other tracts had similar loadings.

Since it has been suggested that a single, general factor may not be an adequate representation of FA variance in brain-wide white matter tracts (Lövdén et al., 2013), we tested the fit of the onefactor solution at each wave. This general factor model initially showed poor fit to the data (at age 73 years: $\chi^{2}(54)=368.60, p<$ 0.001 ; root mean square error of approximation (RMSEA) $=$ 0.093 , comparative fit index $(\mathrm{CFI})=0.86$; Tucker-Lewis index $(\mathrm{TLI})=0.83$; at age 76 years: $\chi^{2}(54)=238.10, p<0.001$; RM$\mathrm{SEA}=0.086$; CFI $=0.86$; $\mathrm{TLI}=0.82)$, but after the inclusion of five residual correlations between the left and right hemisphere measurements of the bilateral white matter tracts, the fit was excellent at age 73 years $\left(\chi^{2}(49)=100.12, p<0.001\right.$; RMSEA $=$ $0.040, \mathrm{CFI}=0.98$; TLI $=0.97)$ and at age 76 years $\left(\chi^{2}(49)=\right.$
Table 4. Results from the structural model of the multivariate latent change model of white matter $\mathrm{FA}, g_{\mathrm{f}}$, memory, and processing speed (for speed, higher values indicate better scores)

\begin{tabular}{|c|c|c|c|c|}
\hline $\begin{array}{l}\text { Path type } \\
\text { (correlation) }\end{array}$ & Path & Estimate & SE & $p$ value \\
\hline \multirow[t]{6}{*}{ Level-level } & $\mathrm{FA}-g_{f}$ & 0.192 & 0.047 & $<0.001$ \\
\hline & FA-speed & 0.240 & 0.046 & $<0.001$ \\
\hline & FA-memory & 0.106 & 0.053 & 0.045 \\
\hline & $g_{f}-$ speed & 0.603 & 0.039 & $<0.001$ \\
\hline & $g_{f}$-memory & 0.875 & 0.037 & $<0.001$ \\
\hline & Speed-memory & 0.593 & 0.045 & $<0.001$ \\
\hline \multirow[t]{16}{*}{ Level-change $(\Delta)$} & $\mathrm{FA}-\Delta \mathrm{FA}$ & -0.414 & 0.053 & $<0.001$ \\
\hline & $\mathrm{FA}-\Delta g_{f}$ & -0.072 & 0.093 & 0.444 \\
\hline & $\mathrm{FA}-\Delta$ speed & 0.153 & 0.070 & 0.029 \\
\hline & $\mathrm{FA}-\Delta$ memory & -0.078 & 0.067 & 0.246 \\
\hline & $g_{f}-\Delta g_{f}$ & -0.041 & 0.096 & 0.670 \\
\hline & $g_{f}-\Delta \mathrm{FA}$ & -0.076 & 0.066 & 0.252 \\
\hline & $g_{f}-\Delta$ speed & 0.189 & 0.067 & 0.005 \\
\hline & $g_{f}-\Delta$ memory & 0.073 & 0.066 & 0.267 \\
\hline & Speed- $\Delta$ speed & -0.091 & 0.077 & 0.238 \\
\hline & Speed- $\Delta \mathrm{FA}$ & 0.036 & 0.072 & 0.614 \\
\hline & Speed- $-\Delta g_{f}$ & 0.155 & 0.097 & 0.108 \\
\hline & Speed- $\Delta$ memory & 0.095 & 0.069 & 0.166 \\
\hline & Memory- $\Delta$ memory & -0.114 & 0.081 & 0.159 \\
\hline & Memory- $\Delta \mathrm{FA}$ & 0.007 & 0.077 & 0.928 \\
\hline & Memory- $\Delta g_{f}$ & 0.026 & 0.109 & 0.813 \\
\hline & Memory- $\Delta$ speed & 0.129 & 0.079 & 0.104 \\
\hline \multicolumn{5}{|l|}{ Change $(\Delta)$ - } \\
\hline \multirow[t]{6}{*}{ change $(\Delta)$} & $\Delta \mathrm{FA}-\Delta g_{f}$ & 0.312 & 0.123 & 0.011 \\
\hline & $\Delta \mathrm{FA}-\Delta$ speed & -0.061 & 0.094 & 0.512 \\
\hline & $\Delta \mathrm{FA}-\Delta$ memory & 0.034 & 0.090 & 0.701 \\
\hline & $\Delta g_{f}-\Delta$ speed & 0.645 & 0.159 & $<0.001$ \\
\hline & $\Delta g_{f}-\Delta$ memory & 0.637 & 0.128 & $<0.001$ \\
\hline & $\Delta$ Speed- $\Delta$ memory & 0.561 & 0.086 & $<0.001$ \\
\hline
\end{tabular}

Full model diagram shown in Figure 2. Results taken from the model are adjusted for age at testing and sex Estimates are standardized.

$80.75, p<0.001 ;$ RMSEA $=0.037 ; \mathrm{CFI}=0.98 ; \mathrm{TLI}=0.97)$. That is, the initially poor fit occurred because bilateral similarities were not taken into account. We included these cross-hemisphere correlations in the final model.

A latent difference score model including only the three cognitive variables had acceptable fit to the data: $\chi^{2}(49)=874.15$, $p<0.001 ; \mathrm{RMSEA}=0.055, \mathrm{CFI}=0.94, \mathrm{TLI}=0.93$. The latent difference score model for FA alone had a slightly poorer fit: $\chi^{2}(252)=626.18, p<0.001 ;$ RMSEA $=0.046$, CFI $=0.92$, TLI $=0.91$. The full, multivariate model (including the three cognitive domains along with FA) showed acceptable fit by all indices, as follows: $\chi^{2}(1056)=2096.182, p<0.001$; RMSEA $=$ $0.034 ; \mathrm{CFI}=0.927 ; \mathrm{TLI}=0.922$. The results from this latter, final model are shown in Table 4 and Figure 3.

At baseline, the cognitive latent factors were strongly related to each other (all $r$ values $>0.59, p$ values $<0.001$; Fig. $3 a$ ). The brain white matter FA factor was significantly associated with all three cognitive domains at baseline (FA with processing speed: $r=0.24, p<0.001$; with $g_{f}: r=0.19, p<0.001$; and with memory: $r=0.11, p=0.045)$. FA had a significantly stronger baseline relation with speed than with memory $\left(\chi^{2}(1)=4.01\right.$, $p=0.045)$, but there were no significant differences in the size of the FA-speed correlation and the FA- $g_{f}$ correlation $\left(\chi^{2}(1)=\right.$ $1.11, p=0.29)$, or between the FA- $g_{f}$ correlation and the FAmemory correlation $\left(\chi^{2}(1)=0.48, p=0.49\right)$.

There was significant decline in the three cognitive and white matter FA factors between age 73 years and age 76 years, as follows: FA $(-0.09$ SDs/year; $z=-5.50, p<0.001), g_{f}(-0.07$ 


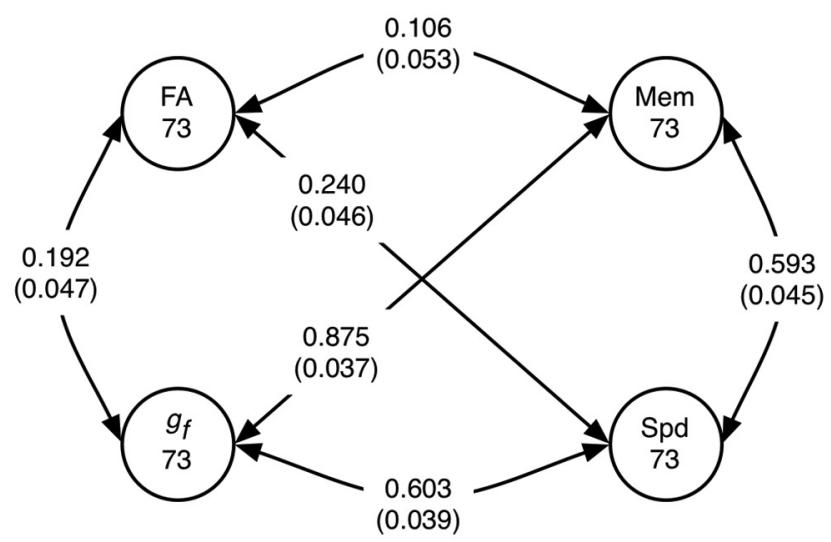

b

Baseline/change correlations

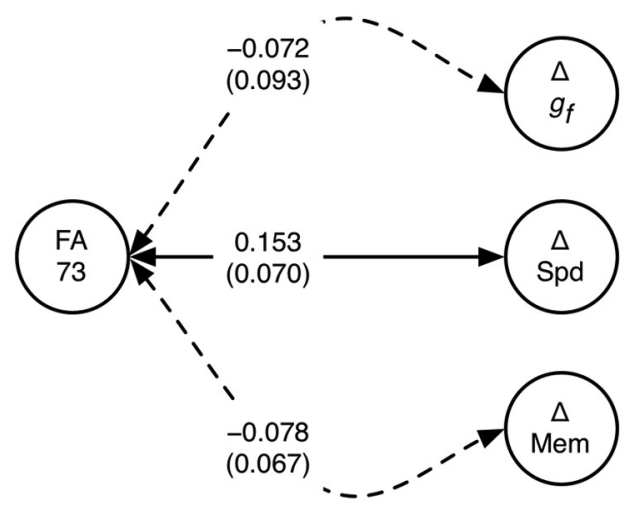

C

Change/change correlations (age $\sim 73$ to age $\sim 76$ )

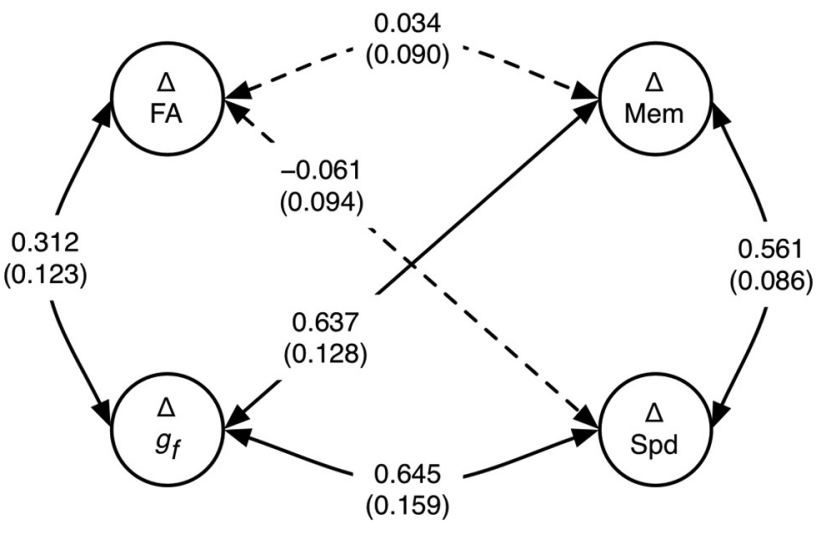

Figure 3. Results from key parts of the latent difference score model. The full model is shown in Figure 2. Full results with significance levels are shown in Table 3 (measurement models; i.e., loadings of each test/tract on its general factor) and Table 4 (structural model; i.e., associations among the baseline and change latent traits). Correlations among latent variables (circles) of brain-wide white matter FA, $g_{f t}$ processing speed (Spd), and memory (Mem) are shown as values on each path (line), with SE in parentheses. Dashed paths are not statistically significant. $\boldsymbol{a}$, All four latent variables were correlated significantly and positively at baseline. $\boldsymbol{b}$, Baseline FA was correlated with the change in processing speed between ages $\sim 73$ and $\sim 76$ years, but not with the change in $g_{f}$ or memory. $c$, Change $(\Delta)$ in FA and $g_{f}$ were positively correlated. Changes in $g_{t r} S p d$, and Mem were all significantly and strongly correlated.

SDs/year; $z=-5.72, p<0.001)$; memory $(-0.06$ SDs/year; $z=$ $-4.66, p<0.001)$; and speed $(-0.15$ SDs/year; $z=-10.39, p<$ $0.001)$. The declines in the cognitive factors were all correlated together (all $r$ values $>0.55, p$ values $<0.001$ ). That is, those who declined more in one cognitive domain also tended to decline more in the other two cognitive domains.

Those with higher FA at age 73 years tended to decline less in speed between ages 73 and 76 years $(r=0.15, p=0.03$; Fig. $3 b)$. There were no significant correlations between baseline FA and change in $g_{f}(r=-0.07, p=0.44)$ or memory $(r=-0.08, p=$ 0.25 ). The correlation between baseline FA and speed change was significantly larger than that between baseline FA and memory change $\left(\chi^{2}(1)=5.16, p=0.02\right)$, but did not differ from that between baseline FA and $g_{f}$ change $\left(\chi^{2}(1)=1.76, p=0.19\right)$.

There was a significant association between the change in brain white matter FA and the change in $g_{f}(r=0.31, p=0.01)$ from 73 to 76 years of age; decrements in brain white matter microstructure were thus coupled with decrements in fluid intelligence over this period (Fig. $3 c$ ). The correlations between the change in FA and the change in memory $(r=0.03, p=0.70)$, and in processing speed $(r=-0.06, p=0.51)$, were very small and nonsignificant; both of these correlations were significantly smaller than the correlation between FA change and $g_{f}$ change (test for differences from the FA change correlation with memory change: $\chi^{2}(1)=4.13, p=0.04$; and with speed change: $\chi^{2}(1)=$ 5.97, $p=0.02$ ).

As a robustness check, we removed all the participants who scored below 24 at either of the waves at age 73 years or age 76 years on the Mini-Mental State Examination (Folstein et al., 1975), a commonly used screening instrument for possible dementia that was administered at both waves. After exclusion of these 13 participants, the model fit was still acceptable $(\mathrm{RMSEA}=0.034, \mathrm{TLI}=0.924, \mathrm{CFI}=0.919)$, and the main associations between the latent variables, as well as the factor loadings, were very similar to those in the original model (all significant associations from the original model remained so; e.g., FA change $-g_{f}$ change correlation: $r=0.32, p=0.01$; baseline FA-speed change correlation, $r=0.20, p=0.01$ ).

Finally, because approximately one-third of the participants who had an MRI scan at age 73 years did not return for a scan at age 76 years (a loss of 241 participants), we tested whether their cognitive or FA measurements differed significantly at baseline from those who remained in the study. To do this, we compared the fit of multigroup models of the baseline (age 73 years) data where the means were constrained to equality between those who returned at age 76 years and those who did not, to models where the means were estimated freely across the groups. For cognitive abilities, a model where the means were constrained had significantly poorer fit $\left(\chi^{2}(12)=28.96, p=0.003\right)$; those participants who did not return at age 76 years had significantly lower cognitive ability. The participants who went on to drop out also had lower FA values, but this difference was not significant $\left(\chi^{2}(12)=\right.$ $18.58, p=0.10)$.

\section{Discussion}

The present results show that aging-related deterioration in the microstructure of brain white matter connections is coupled with a decline in general fluid intelligence, which reflects the important skills of reasoning, problem solving, and working memory. White matter connections allow rapid information transfer between gray matter regions that are critical for high-level cognitive operations (Filley, 2012). This result is thus among the strongest evidence to date that is consistent with the theory that corticocortical "disconnection" is a cause of aging-related cognitive decline (Geschwind, 1965, O’Sullivan et al., 2001; Chanraud et al., 2010).

The cognitive trait of processing speed had numerically the strongest baseline correlation with white matter FA, and showed 
the most pronounced decline with age. There was no significant association between change in FA and change in speed. However, there was a significant association between higher baseline white matter FA and a less steep decline in processing speed. This latter result has implications for the "brain reserve" hypothesis (Christensen et al., 2007), since it suggests that those with initially higher brain white matter FA maintain their processing speed more effectively as they age.

White matter FA may be reduced in older age via a number of neurobiological processes, including microvascular damage, degeneration of myelin sheaths around axons, decreasing axonal density, and breakdown of the cytoskeleton (Sullivan and Pfefferbaum, 2006; Madden et al., 2012), all of which may be important for more efficient complex cognition. Alternatively, FA declines may be secondary effects caused by white matter atrophy (Vernooij et al., 2008; Aribisala et al., 2013) or by aging-related changes in the extracellular matrix (Syková, 2005). Analyzing the change in other MRI biomarkers-such as axial and radial diffusivity, T1 for water content, and magnetization transfer ratio (Penke et al., 2010, 2012)—may reveal more about the relation between white matter deterioration and cognitive decline, although it should be noted that equating specific DT-MRI measurements with precise cellular mechanisms is inadvisable (Wheeler-Kingshott and Cercignani, 2009; Jones et al., 2013).

The data examined here are unusual in that they are longitudinal and that they contain a wide range of cognitive tests taken alongside detailed neuroimaging measures in a very large sample. The narrow age range at each measurement wave is also important, since it rules out the confounder of chronological age (Hofer and Sliwinski, 2001). Our use of the Latent Difference Score model (McArdle, 2009) also allowed error-free estimates of the longitudinal changes in the brain and cognitive abilities. Our results are thus likely to be highly robust, but the study also has some limitations. First, since the power to detect a correlated change in longitudinal studies increases dramatically with greater study durations (Rast and Hofer, 2014), we might expect studies across even longer time periods than the 3 years covered here, with a greater number of testing waves at older ages, to uncover other possible effects that are of interest. There may also be nonlinear changes in white matter microstructure across aging (Kochunov et al., 2012); it would be possible to test for these using three or more waves of data, but we could not do so with the two-wave data in the present study. Tests of these hypotheses will become viable in this sample as new waves of Lothian Birth Cohort 1936 data are collected.

Second, as noted above, a previous study found that a general factor was a poorer fitting model of individual differences in tract FA values from across the brain, when compared with a model that modeled tracts individually (Lövdén et al., 2013). We found excellent fit with a single-factor model that also accounted for bilaterally measured tracts, but this does not preclude the possibility that variance in the FA changes of specific tracts may provide additional information about cognitive decline (for cross-sectional analyses of specific tracts in the present cohort, see Booth et al., 2013).

Third, given that our sample was somewhat self-selecting, and thus likely healthier and of higher cognitive ability than similarlyaged individuals in the general population, our results may not be fully generalizable. Relatedly, our dropout analysis indicated that participants who did not return for the second MRI scan had significantly lower cognitive ability levels than those who remained; there was thus some restriction of range at the second wave. We might thus expect the true correlations to be somewhat larger in a fully representative sample. Fourth, the broadly healthy nature of our participants also means that our results do not directly address the etiologies of Alzheimer's disease and other dementia-related neuropathologies. However, as noted above, understanding nonpathological aging-related cognitive decline is important (Boyle et al., 2013); since accelerated decline in some cases predicts pathology (Mura et al., 2014), these results may shed light on the prodromal phase of these disorders. Fifth, our results are not fully comparable to the previous two longitudinal studies of white matter and cognitive abilities discussed above (Charlton et al., 2010; Lövdén et al., 2014), which used different cognitive tests and participants who were both younger and older than those in our sample. Nonetheless, these studies converge with ours on the finding that white matter microstructure changes with age in tandem with cognitive abilities.

It should be noted that the intrafactor correlations between baseline and change in our model (e.g., the correlation between baseline FA and change in FA) were negative, indicating that those with higher baseline scores tended to decline more quickly. These results are most likely due to the "law of initial value" (Wilder, 1957); they reflect the fact that there are more ways for a high baseline score than for a low baseline score to decline (these correlations may also reflect regression to the mean caused by measurement error, but, as noted above, measurement error was minimized by our use of latent variables). This is not the case for interfactor baseline-change correlations; for instance, the significant correlation between baseline FA and change in speed.

The present analysis suggests that one of the mechanisms explaining differences in aging-related decline in fluid intelligence is indexed by deteriorating brain white matter FA, and that poorer FA is linked to more subsequent decline in cognitive processing speed. We found no associations of either baseline or change in FA with the change in memory. Future models of the association between declining white matter microstructure and cognitive aging should take into account not only the alternative imaging biomarkers discussed above, but also the accumulation of white matter hyperintensities (Fazekas et al., 1993), which may index damage to surrounding normal-appearing white matter tracts. A complete understanding of the neural basis of cognitive decline will not, however, be limited to these measures. Additional indicators of brain health, such as global atrophy and loss of tissue in specific structures (Salthouse, 2011; Aribisala et al., 2013), cortical thinning (Burzynska et al., 2012), vascular mineralization and small-vessel disease (Glatz et al., 2013), reduced functional connectivity (Mandl et al., 2008; Ferreira and Busatto, 2013), and reduced structural connectivity (Lawrence et al., 2014), as well as lower-level synaptic variation (Morrison and Baxter, 2014) are all plausible candidates to explain portions of variance in the aging of cognitive functions. Future studies investigating these parameters using similar samples and modeling techniques to those used here can build on the lead of the present study in understanding the biological basis of cognitive aging.

\section{References}

Aribisala BS, Valdés Hernández MC, Royle NA, Morris Z, Muñoz Maniega S, Bastin ME, Deary IJ, Wardlaw JM (2013) Brain atrophy associations with white matter lesions in the ageing brain: the Lothian Birth Cohort 1936. Eur Radiol 23:1084-1092. CrossRef Medline

Bastin ME, Muñoz Maniega S, Ferguson KJ, Brown LJ, Wardlaw JM, MacLullich AM, Clayden JD (2010) Quantifying the effects of normal ageing on white matter structure using unsupervised tract shape modelling. Neuroimage 51:1-10. CrossRef Medline

Behrens TE, Berg HJ, Jbabdi S, Rushworth MF, Woolrich WM (2007) Prob- 
abilistic diffusion tractography with multiple fibre orientations: what can we gain? Neuroimage 34:144-155. CrossRef Medline

Bennett IJ, Madden DJ (2014) Disconnected aging: cerebral white matter integrity and age-related differences in cognition. Neuroscience 276:187205. CrossRef Medline

Booth T, Bastin ME, Penke L, Maniega SM, Murray C, Royle NA, Gow AJ, Corley J, Henderson RD, Starr JM, Wardlaw JM, Deary IJ (2013) Brain white matter tract integrity and cognitive abilities in community-dwelling older people: the Lothian Birth Cohort, 1936. Neuropsychology 27:595607. CrossRef Medline

Borghesani PR, Madhyastha TM, Aylward EH, Reiter MA, Swarny BR, Warner Schaie KW, Willis SL (2013) The association between higher order abilities, processing speed, and age are variably mediated by white matter integrity during typical aging. Neuropsychologia 51:1435-1444. CrossRef Medline

Boyle PA, Wilson RS, Yu L, Barr AM, Honer WG, Schneider JA, Bennett DA (2013) Much of late life cognitive decline is not due to common neurodegenerative pathologies. Ann Neurol 74:478-489. CrossRef Medline

Burzynska AZ, Nagel IE, Preuschhof C, Gluth S, Bäckman L, Li SC, Lindenberger U, Heekeren HR (2012) Cortical thickness is linked to executive functioning in adulthood and aging. Hum Brain Mapp 33:1607-1620. CrossRef Medline

Carroll JB (1993) Human cognitive abilities: a survey of factor-analytic studies. Cambridge, UK: Cambridge UP.

Chanraud S, Zahr N, Sullivan EV, Pfefferbaum A (2010) MR diffusion tensor imaging: a window into white matter integrity of the working brain. Neuropsychol Rev 20:209-225. CrossRef Medline

Charlton RA, Schiavone F, Barrick TR, Morris RG, Markus HS (2010) Diffusion tensor imaging detects age related white matter change over a 2 year follow-up which is associated with working memory decline. J Neurol Psychiatr 81:13-19. CrossRef

Christensen H, Anstey KJ, Parslow RA, Maller J, Mackinnon A, Sachdev P (2007) The brain reserve hypothesis, brain atrophy and aging. Gerontology 53:82-95. CrossRef Medline

Clayden JD, Storkey AJ, Muñoz Maniega S, Bastin ME (2009) Reproducibility of tract segmentation between sessions using an unsupervised modelling-based approach. Neuroimage 45:377-385. CrossRef Medline

Clayden JD, Muñoz Maniega SM, Storkey AJ, King MD, Bastin ME, Clark CA (2011) TractoR: magnetic resonance imaging and tractography with R. J Stat Softw 44:1-18

Deary IJ, Der G, Ford G (2001) Reaction times and intelligence differences: a population-based cohort study. Intelligence 29:389-399. CrossRef

Deary IJ, Simonotto E, Meyer M, Marshall A, Marshall I, Goddard N, Wardlaw JM (2004) (2004) The functional anatomy of inspection time: an event-related fMRI study. Neuroimage 22:1466-1479. CrossRef Medline

Deary IJ, Gow AJ, Taylor MD, Corley J, Brett C, Wilson V, Campbell H, Whalley LJ, Visscher PM, Porteous DJ, Starr JM (2007) The Lothian Birth Cohort 1936: a study to examine influences on cognitive ageing from age 11 to age 70 and beyond. BMC Geriatr 7:28. CrossRef Medline

Deary IJ, Gow AJ, Pattie A, Starr JM (2012) Cohort profile: the Lothian Birth Cohorts of 1921 and 1936. Int J Epidemiol 41:1576-1584. CrossRef Medline

Fazekas F, Kleinert R, Offenbacher H, Schmidt R, Kleinert G, Payer F, Radner H, Lechner H (1993) Pathologic correlates of incidental MRI white matter signal hyperintensities. Neurology 43:1683-1689. CrossRef Medline

Ferreira LK, Busatto GF (2013) Resting-state functional connectivity in normal brain aging. Neurosci Biobehav Rev 37:384-400. CrossRef Medline

Filley CM (2012) The behavioral neurology of white matter, Ed 2. Oxford, UK: Oxford UP.

Folstein MF, Folstein SE, McHugh PR (1975) "Mini-mental state": a practical method for grading the cognitive state of patients for the clinician. J Psychiatr Res 12:189-198. CrossRef Medline

Geschwind N (1965) Disconnexion syndromes in animals and man. Brain 88:585-644. CrossRef Medline

Glatz A, Valdés Hernández MC, Kiker AJ, Bastin ME, Deary IJ, Wardlaw JM (2013) Characterization of multifocal T2*-weighted MRI hypointensities in the basal ganglia of elderly, community-dwelling subjects. Neuroimage 82:470-480. CrossRef Medline

Grieve SM, Williams LM, Paul RH, Clark CR, Gordon E (2007) Cognitive aging, executive function, and fractional anisotropy: a diffusion tensor MR imaging study. Am J Neuroradiol 28:226-235. Medline
Hofer SM, Sliwinski MJ (2001) Understanding ageing: an evaluation of research designs for assessing the interdependence of ageing-related changes. Gerontology 47:341-352. CrossRef Medline

Jones DK, Griffin LD, Alexander DC, Catani M, Horsfield MA, Howard R, Williams SC (2002) Spatial normalization and averaging of diffusion tensor MRI data sets. Neuroimage 17:592-617. CrossRef Medline

Jones DK, Knösche TR, Turner R (2013) White matter integrity, fiber count, and other fallacies: the do's and don'ts of diffusion MRI. Neuroimage 73:239-254. CrossRef Medline

Kievit RA, Davis SW, Mitchell DJ, Taylor JR, Duncan J, Henson RN (2014) Distinct aspects of frontal lobe structure mediate age-related differences in fluid intelligence and multitasking. Nat Commun 5:5658. CrossRef Medline

Kochunov P, Williamson DE, Lancaster J, Fox P, Cornell J, Blangero J, Glahn DC (2012) Fractional anisotropy of water diffusion in cerebral white matter across the lifespan. Neurobiol Aging 33:9-20. CrossRef Medline

Lawrence AJ, Chung AW, Morris RG, Markus HS, Barrick TR (2014) Structural network efficiency is associated with cognitive impairment in smallvessel disease. Neurology 83:304-311. CrossRef Medline

Le Bihan D (2003) Looking into the functional architecture of the brain with diffusion MRI. Nat Rev Neurosci 4:469-480. CrossRef Medline

Lebel C, Gee M, Camicioli R, Wieler M, Martin W, Beaulieu C (2012) Diffusion tensor imaging of white matter tract evolution over the lifespan. Neuroimage 60:340-352. CrossRef Medline

Lövdén M, Laukka EJ, Rieckmann A, Kalpouzos G, Li TQ, Jonsson T, Wahlund LO, Fratiglioni L, Bäckman L (2013) The dimensionality of between-person differences in white matter microstructure in old age. Hum Brain Mapp 34:1386-1398. CrossRef Medline

Lövdén M, Köhncke Y, Laukka EJ, Kalpouzos G, Salami A, Li TQ, Fratiglioni L, Bäckman L (2014) Changes in perceptual speed and white matter microstructure in the corticospinal tract are associated in very old age. Neuroimage 102:520-530. CrossRef Medline

Madden DJ, Spaniol J, Costello MC, Bucur B, White LE, Cabeza R, Davis SW, Dennis NA, Provenzale JM, Huettel SA (2009) Cerebral white matter integrity mediates adult age differences in cognitive performance. J Cogn Neurosci 21:289-302. CrossRef Medline

Madden DJ, Bennett IJ, Burzynska A, Potter GG, Chen N, Song AW (2012) Diffusion tensor imaging of cerebral white matter integrity in cognitive ageing. BBA Mol Basis Dis 1822:386-400. CrossRef

Mandl RCW, Schnack HG, Zwiers MP, van der Schaaf A, Kahn RS, Hulshoff Pol HE (2008) Functional diffusion tensor imaging: measuring taskrelated fractional anisotropy changes in the human brain along white matter tracts. PLoS One 3:e3631. CrossRef Medline

McArdle JJ (2009) Latent variable modeling of differences and changes with longitudinal data. Annu Rev Psychol 60:577-605. CrossRef Medline

Morrison JH, Baxter MG (2014) Synaptic health. JAMA Psychiatr 71:835837. CrossRef Medline

Mura T, Proust-Lima C, Jacqmin-Gadda H, Akbaraly TN, Touchon J, Dubois B, Berr C (2014) Measuring cognitive change in subjects with prodromal Alzheimer's disease. J Neurol Neurosurg Psychiatry 85:363-370. CrossRef Medline

Muthén LK, Muthén BO (1998-2014) Mplus user's guide: the comprehensive modeling program for applied researchers. Los Angeles: Muthén \& Muthén.

O'Sullivan M, Jones DK, Summers PE, Morris RG, Williams SC, Markus HS (2001) Evidence for cortical "disconnection" as a mechanism of agerelated cognitive decline. Neurology 57:632-638. CrossRef Medline

Penke L, Muñoz Maniega S, Murray C, Gow AJ, Hernández MC, Clayden JD, Starr JM, Wardlaw JM, Bastin ME, Deary IJ (2010) A general factor of brain white matter integrity predicts information processing speed in healthy older people. J Neurosci 30:7569-7574. CrossRef Medline

Penke L, Muñoz Maniega S, Bastin ME, Valdés Hernandez MV, Murray C, Royle NA, Starr JM, Wardlaw JM, Deary IJ (2012) Brain white matter tract integrity as a neural foundation for general intelligence. Mol Psychiatr 17:1026-1030. CrossRef Medline

Pierpaoli C, Jezzard P, Basser PJ, Barnett A, Di Chiro G (1996) Diffusion tensor MR imaging of the human brain. Radiology 201:637-648. CrossRef Medline

Rast P, Hofer SM (2014) Longitudinal design considerations to optimize power to detect variances and covariances among rates of change: simu- 
lation results based on actual longitudinal studies. Psychol Methods 19: 133-154. CrossRef Medline

Raz N, Lindenberger U (2011) Only time will tell: cross-sectional studies offer no solution to the age-brain-cognition triangle: comment on Salthouse (2011). Psychol Bull 137:790-795. CrossRef Medline

Salat DH, Tuch DS, Hevelone ND, Fischl B, Corkin S, Rosas HD, Dale AM (2005) Age-related changes in prefrontal white matter measured by diffusion tensor imaging. Ann NY Acad Sci 1064:37-49. CrossRef Medline

Salthouse TA (2011) Neuroanatomical substrates of age-related cognitive decline. Psychol Bull 137:753-784. CrossRef Medline

Scottish Council for Research in Education (1949) The trend of Scottish intelligence. London, UK: University of London.

Sullivan EV, Pfefferbaum A (2006) Diffusion tensor imaging and aging. Neurosci Biobehav Rev 30:749-761. CrossRef Medline

Sullivan EV, Rohlfing T, Pfefferbaum A (2010) Longitudinal study of callosal microstructure in the normal adult aging brain using quantitative DTI fiber tracking. Dev Neuropsychol 35:233-256. CrossRef Medline

Syková E (2005) Glia and volume transmission during physiological and pathological states. J Neural Transm 112:137-147. CrossRef Medline

Turken A, Whitfield-Gabrieli S, Bammer R, Baldo JV, Dronkers NF, Gabrieli JD (2008) Cognitive processing speed and the structure of white matter pathways: convergent evidence from normal variation and lesion studies. Neuroimage 42:1032-1044. CrossRef Medline
Vernooij MW, de Groot M, van der Lugt A, Ikram MA, Krestin GP, Hofman A, Niessen WJ, Breteler MM (2008) White matter atrophy and lesion formation explain the loss of structural integrity of white matter in aging. Neuroimage 43:470-477. CrossRef Medline

Voineskos AN, Rajji TK, Lobaugh NJ, Miranda D, Shenton ME, Kennedy JL, Pollock BG, Mulsant BH (2012) Age-related decline in white matter tract integrity and cognitive performance: a DTI tractography and structural equation modeling study. Neurobiol Aging 33:21-34. CrossRef Medline

Wardlaw JM, Bastin ME, Valdés Hernández MC, Maniega SM, Royle NA, Morris Z, Clayden JD, Sandeman EM, Eadie E, Murray C, Starr JM, Deary IJ (2011) Brain aging, cognition in youth and old age and vascular disease in the Lothian Birth Cohort 1936: rationale, design and methodology of the imaging protocol. Int J Stroke 6:547-559. CrossRef Medline

Wechsler D (1998) Wechsler Adult Intelligence Scale III-UK administration and scoring manual. London, UK: Psychological Corporation.

Wheeler-Kingshott CA, Cercignani M (2009) About "axial" and "radial" diffusivities. Magn Reson Med 61:1255-1260. CrossRef Medline

Widaman KF, Ferrer E, Conger RD (2010) Factorial invariance within longitudinal structural equation models: measuring the same construct across time. Child Dev Perspect 4:10-18. CrossRef Medline

Wilder J (1957) The law of initial value in neurology and psychiatry: facts and problems. J Nerv Ment Dis 125:73-86. CrossRef Medline 